\title{
Altitude Training and Endurance and Ultra-Endurance Performance
}

\author{
M. Marzorati
}

Institute of Biomedical Technologies, National Research Council, Milan, Italy

\section{CORRESPONDING AUTHOR:}

\section{Mauro Marzorati}

Institute of Biomedical Technologies

National Research Council

LITA Building, via Fratelli Cervi 93, I

20090 Segrate, (MI), Italy

E-mail: mauro.marzorati@itb.cnr.it

DOI:

10.32098/mltj.02.2020.11

LEVEL OF EVIDENCE: $2 a$

\begin{abstract}
SUMMARY
Background. Altitude training has been shown to improve endurance and ultra-endurance performance at altitude, whereas the possible benefits from altitude/hypoxic training for competing at sea level have been, and still are, a matter for debate. Reasons for this discrepancy may result from the variety of protocols utilized in terms of altitude, natural or simulated, to which the athletes were exposed, and amount of the time spent at altitude. In order to conciliate previous findings and provide practical recommendations to athletes, the concept of optimal "hypoxic dose" has been defined. Methods. To perform a review of the literature concerning the effects of altitude training on athletic performance.

Results. The dominant paradigm is that the improved performance at sea level is due primarily to an accelerated erythropoiesis due to the reduced oxygen available at altitude, leading to an increase in red cell mass. Indeed, in recent years it has become evident that other non-hematological factors (improved muscle efficiency, greater muscle buffering capacity, etc.), may contribute to improve athletic performance.

Conclusions. Despite more than fifty years of research and studies, altitude training remains a controversial issue and yet, there are many unanswered questions.
\end{abstract}

\section{KEY WORDS}

Endurance performance; haemoglobin; Live High-Train Low; neocytolysis

\section{INTRODUCTION}

Altitude/hypoxic training has been used since the 1960s by endurance athletes in an attempt to improve sea level performance. The original method of altitude/hypoxic training was one in which athletes lived and trained at moderate altitude $(1500-3000 \mathrm{~m})$, for the purpose of increasing erythrocyte volume and ultimately enhancing sea-level maximal oxygen uptake $\left(\mathrm{VO}_{2 \max }\right)$ and endurance performance. Live high - train high (LHTH) altitude training is still used today by sea level athletes who complete altitude training camps at specific times during the training year (1), and of course by altitude residents, such as the Kenyan and Ethiopian runners. However, one major conclusion drawn from both anecdotal and scientific evidence regarding LHTH altitude training, was that endurance athletes did not seem able to train at an equivalent or near-equivalent training intensity (e.g., running velocity) as compared with sea-level training. Thus, there may be a detraining effect associated with LHTH, which likely accounts for the evidence that, when appropri- ate control groups have been included, living and training at altitude have not been proven to be advantageous compared with equivalent training at sea level (2).

To overcome this limitation, Levine and Stray-Gundersen (3) proposed the "live high train-low" (LHTL) model about twenty years ago. The general idea was that if athletes could live and sleep at altitude but train at sea level, they could acquire the physiological advantages of altitude acclimatization for maximizing oxygen carrying capacity, without the detraining associated with hypoxic exercise. In their original study (3), 39 college runners underwent 2 weeks of lead-in training and 4 weeks of controlled sea-level training where after the subjects were randomly assigned to 4 weeks of either living at $2500 \mathrm{~m}$ and training at $2500-2700 \mathrm{~m}$ (LHTH), living and training at sea level (Control), or living at $2500 \mathrm{~m}$ while training at lower altitudes between 1200 and $1400 \mathrm{~m}$ (LHTL). Following the various training camps, $\mathrm{VO}_{2 \max }$ was increased with LHTH and LHTL, but $5000 \mathrm{~m}$ running performance was only significantly increased in the LHTL group (3). 
Over the last two decades, a large amount of research has been conducted adopting the LHTL approach in endurance athletes of different disciplines and competitive level, leading to controversial results. Several studies $(4,5,6,7)$ and meta-analyses (8) support the sea level performance benefit of properly executed LHTL altitude training, whereas others have failed to do so (9) and question the usefulness of this practice $(10,11)$.

At a glance, most of these studies have used small sample sizes and present limitations in the study design, such as the lack of a control group, that do not allow to rule out the occurrence of placebo, nocebo and training camp effects $(8,10)$. Numerous reasons may explain this discrepancy. Because the geography of many countries does not readily permit LHTL and due to practical (logistically and financially) constraints, it may not be convenient for athletes to spend time at natural altitude. To overcome this potential problem, studies have been conducted substituting "terrestrial" altitude exposure (hypobaric hypoxia) with the use of 'nitrogen housing', where indoor living areas are flushed with $\mathrm{N}_{2}$, or use of molecular oxygen sieves to decrease $\mathrm{FIO}_{2}$ and thus stimulate exposure to high altitude (normobaric hypoxia). Whereas, it seems that for the same inspired partial pressure of oxygen, the erythropoietic responses leading to the increase in haemoglobin mass is similar (12), others various biological markers such as ventilation and nitric oxide metabolism show a different behavior (13). While still largely debated $(14,15)$, it currently remains unresolved if normobaric and hypobaric hypoxic exposure elicit different physiological or pathophysiological responses.

Another factor to be considered is the iron status of the athletes involved in these studies. As reported by Stray-Gundersen et al., (1992) (16), no increase in red cell mass (RCM) or $\mathrm{VO}_{2 \max }$ occurred in nine iron-deficient distance runners (serum ferritin $<30 \mathrm{ng} / \mathrm{mL}$ for men, $<20 \mathrm{ng} / \mathrm{mL}$ for women, before departure) after 4 weeks at $2500 \mathrm{~m}$, while athletes with adequate ferritin levels pre altitude demonstrated significant increases in RCM and $\mathrm{VO}_{2 \max }$ post altitude camp. Indeed, emerging data suggest that iron supplementation may be a necessary requirement for adequate erythropoiesis with altitude exposure (17). In turn, this may explain why some of those studies failed to demonstrate improvements in $\mathrm{VO}_{2 \max }$ or performance following altitude training.

Regardless of iron status pre altitude, individual variability in the response to altitude/hypoxic exposure is an important factor that needs to be accounted for when planning altitude training and specific living/training elevations (18). Different responses between athletes have been reported for various parameters such as the EPO response to both shortand long-term exposure to hypoxia, ventilator acclimatization, and ability to maintain training volumes and intensities at altitude (18). Overall, the balance between those adaptations, or lack thereof, will determine whether the athlete will experience improvements in $\mathrm{VO}_{2 \max }$ and performance following chronic hypoxic exposure. In this regard, ongoing research is devoted to identify the specific characteristics (genotype or phenotype) that influence the observed individual variation in the altitude/hypoxic acclimatization response.

Interestingly, in attempt to conciliate the inconsistent findings of the literature and to provide practical recommendations to athletes and coaches, the concept of optimal "hypoxic dose" has been defined (19,20). Given the variety of protocols used in LHTL studies in terms of: 1) the altitude-natural or simulated - at which the athlete was exposed; 2) number of days of altitude/hypoxic exposure, and 3) number of hours per day of altitude/ hypoxic exposure, researchers have focused on the question: in using LHTL, what is the optimal hypoxic dose needed to produce the expected beneficial physiological responses and sea-level performance effects in most participants? Obviously, there is no "one size fits all" model when considering altitude training, however Constantini et al., (2017) (17) have recently summarized current best-practice altitude training guidelines to optimize sea level endurance performance. The information provided is based on evidence-based practices from multiple laboratories and anecdotal observations by the authors and others. While the specific response to altitude is highly individualized, following these guidelines and recommendations will help improve the odds of a successful altitude training camp outcome.

\section{Physiological mechanism(s) responsible for the improved performance after altitude training}

Exposure to environments with reduced partial pressure of oxygen $\left(\mathrm{PO}_{2}\right)$ induces a number of physiological adaptations that are potentially beneficial for athletic performance. The prevailing paradigm of adaptation to a lower $\mathrm{O}_{2}$ availability, either in natural or simulated hypoxic environment, is an increased synthesis and release of EPO that, given adequate iron stores, leads to an increased rate of red blood cell production and hemoglobin mass $\left(\mathrm{Hb}_{\text {mass }}\right)$. These hematological changes improve oxygen carrying capacity and are partially responsible for the improvement of sea level $\mathrm{VO}_{2 \max }$. Although some authors have explicitly related the change in sea level performance following an altitude training camp to the change in serum EPO levels ${ }^{3}$, ${ }^{21}$ at altitude, the correlation for the change in $\mathrm{VO}_{2 \max }$ versus the change in red blood cell volume yielded an $\mathrm{r}^{2}=0.137^{3}$. This means that $86 \%$ of the variance in $\mathrm{VO}_{2 \max }$ is attributable to factors other than the change in $\mathrm{Hb}_{\text {mass }}$. Incidental- 
ly, it is important to be aware that $\mathrm{VO}_{2 \max }$ is not the sole determinant of performance. Among elite athletes, other factors such as exercise economy and the fractional utilisation of $\mathrm{VO}_{2 \max }$ are also important determinants of endurance performance ${ }^{22}$. In addition to the increase in $\mathrm{Hb}_{\text {mass }}$, a number of nonhematological factors, such as an enhancement of muscle efficiency and of both muscle buffering and ability to tolerate lactic acid production, have also been proposed to contribute to improved sea level performance following altitude training (see the review of Gore et al., 2007) (23). Consistent with this view, is the observation that high altitude natives have shown a better economy of locomotion than sea level residents (24).

\section{Time to return to sea level}

Another key unanswered question, which is rarely addressed, concerns the proper timing of return to sea level prior to competition (25). So far, researchers have been almost exclusively focused on the mechanisms and time course of altitude acclimatization and there is a paucity of data on the time course of de-acclimatization from altitude. Indeed, mistiming of the return to sea level can potentially result in the athlete performing worse than pre altitude. At present, there is meager evidence based research on optimal timing of return for enhanced sea level performance, and most recommendations are based on anecdotal evidence from coaches. Three physiological mechanisms should be considered when timing the return to sea level prior to competition: (1) red blood cell mass decay, (2) ventilatory acclimatization, and (3) biomechanical/neuromuscular adaptations associated with force production.

With regard to the first and likely most important mechanism, it has recently been observed how the red cell mass (26) or the total $\mathrm{Hb}_{\text {mass }}$ (27) of subjects acclimatized to altitude rapidly decreased by $10 \%$ to $15 \%$ over the first few days after descent to sea level. This physiological process, defined neocytolysis, is characterized by a selective hemolysis of the youngest circulating red blood cells when EPO levels fall below resting baseline levels. Whether periods of intermittent hypoxia, either at night while sleeping or even with the hypobaria of airline travel, could result in enough EPO release to prevent neocytolysis and preserve the hematological acclimatization response for a longer time is matter of future research (25). At present, the proper timing of return to sea level prior to competition remains elusive from a physiological point of view. Given the large individual variability, it is likely that each athlete may display his or her own signature of de-acclimatization with sea level residence, and knowledge of personal decay rates may allow for individualized prescriptions of when best to complete post altitude camp (25).

\section{Preparation for ultra-endurance performance at altitude}

Whereas the possible benefits from altitude/hypoxic training for competing at sea level have been, and still are, a matter for debate, the usefulness of this approach to improve endurance and ultra-endurance performance at altitude cannot be questioned. Given the wide proliferation of ultra-long endurance races held at moderate (for instance the Tor des Géants, a foot race on a distance of $356 \mathrm{~km}$ reaching $3000 \mathrm{~m}$ with a positive altitude difference of 27 $\mathrm{km}$ ) and high altitude (for example the Himal Race 2020, $850 \mathrm{~km}$ distance up to $5364 \mathrm{~m}$ with a positive altitude difference of $40 \mathrm{~km}$ ), it is of paramount importance for athletes engaged in these events to know whether a sojourn at altitude prior to the competition will be useful or not.

It is well established that endurance performance of sea level dwellers is impaired acutely upon arrival at moderate altitude, mainly due to a large drop in arterial oxygen saturation and gradually improves due to ventilatory acclimatization and an increase of the haematocrit. As a result, since the Summer Olympic Games 1968 held in Mexico City, athletes, coaches and mountaineers are required to establish optimal preparation programs for competing at altitude.

From the analysis of the literature, an exposure to hypobaric hypoxia of at least 2 weeks seems to be necessary to achieve a proper acclimatization and compete at the optimal level in ultra-endurance events held at altitudes up to $4,500 \mathrm{~m}$. However, in some situations, such an ideal acclimatization profile cannot be realized for logistical, socioeconomic and/ or individual reasons. When time for a proper acclimatization is not available, a "pre-acclimatization", the exposure of the body to real or simulated altitude for even an intermittent, limited duration, may represent an option. Unfortunately, there is not yet much scientific evidence about the optimal approach (altitude, duration of hypoxia and duration of normoxia between the hypoxic phases) to adopt. In order to reduce the risk of high-altitude illness, the recommended strategy is to remain at an altitude between 2000 and $3000 \mathrm{~m}$ for about a week and to include day hiking or climbing at higher altitudes (28). Profound knowledge and consideration of the individual differences in the physiological responses to a sojourn and training at altitude is essential to coaches, team doctors and athletes for competitive success (29).

\section{CONCLUSIONS}

Although the current scientific evidence is somehow controversial, there is a widespread acceptance that altitude training can enhance endurance performance at sea level. As a matter of fact, since the relative improvement in perfor- 
mance required by an elite athlete to increase their chance of winning medals at international competition is about $0.5 \%(30)$, it is not surprising that with small sample sizes (less than 20 participants), many studies have been underpowered to detect a change of this magnitude using conventional statistics.

Current guidelines for optimal altitude training in order to enhance sea level endurance performance have been recently summarized (17). While the specific response to altitude acclimatization and de-acclimatization is highly individu-

\section{REFERENCES}

1. Pugliese L, Serpiello FR, Millet GP and La Torre A. Training Diaries during Altitude Training Camp in Two Olympic Champions: An Observational Case Study. J Sports Sci Med. 2014; 13:666-672.

2. Adams, W. C., E. M. Bernauer, D. B. Dill, and J. B. Bomar. Effects of equivalent sea-level and altitude training on $\mathrm{V}^{\text {. }}$ O2max and running performance. J. Appl. Physiol. 1975;39: 262-265.

3. Levine BD and Stray-Gundersen J. "Living high training low": effect of moderate-altitude acclimatization with low altitude training on performance. J. Appl. Physiol. 1997;83: 102-112.

4. Chapman RF, Stray-Gundersen J, and Levine BD. Individual variation in response to altitude training. J Appl Physiol. 1998;85: 1448 -1456.

5. Stray-Gundersen J, Chapman RF, and Levine BD. "Living high training low" altitude training improves sea level performance in male and female elite runners. J Appl Physiol. 2001;91: 1113-1120.

6. Brugniaux JV, Schmitt L, Robach P, Nicolet G, Fouillot JP, Moutereau S, Lasne F, Pialoux V, Saas P, Chorvot MC, Cornolo J, Olsen NV and Richalet JP. Eighteen days of "living high, training low" stimulate erythropoiesis and enhance aerobic performance in elite middle distance runners. J Appl Physiol. 2006;100: 203-211.

7. Wehrlin JP, Zuest P, Hallen J and Marti B. Live high-train low for 24 days increases hemoglobin mass and red cell volume in elite endurance athletes. J Appl Physiol. 2006;100: 1938-1945.

8. Bonetti DL and Hopkins WG. Sea-level exercise performance following adaptation to hypoxia: a meta-analysis. Sports Med. 2009;39: 107-127.

9. Siebenmann C, Robach P, Jacobs RA, Rasmussen P, Nordsborg N, Diaz V, Christ A, Olsen NV, Maggiorini M and Lundby C. "Live high-train low" using normobaric hypoxia: a double-blinded, placebo-controlled study. J Appl Physiol. 2012;112: 106-117.

10. Lundby C, Millet GP, Calbet JA, B artsch P and Subudhi AW. Does 'altitude training' increase exercise performance in elite athletes? Br J Sports Med. 2012; 46: 792-795.

11. Lundby $C$ and Robach P. Does 'altitude training' increase exercise performance in elite athletes? Exp Physiol. 2016; 101: 783-788

12. Saugy, JJ, Schmitt L, Cejuela R, Faiss R, Hauser A, Wehrlin J P, Rudaz B, Delessert A, Robinson N, and Millet GP. Compar- alized, following the proposed guidelines and recommendations will help improve the odds of a successful altitude training camp outcome.

More research, with a robust study design, should be done to determine whether or not altitude training leads to improvements in sea level performance.

\section{CONFLICT OF INTERESTS}

The author declares that he has no conflict of interests (31). ison of 'live high-train low' in normobaric versus hypobaric hypoxia. PLoS One. 2014; 9(12), e114418.

13. Faiss, R., Pialoux, v., Sartori, C., Faes, C., Deriaz, O. and Millet, G. P. Ventilation, oxidative stress, and nitric oxide in hypobaric versus normobaric hypoxia. Med Sci Sports Exerc. 2013;45: 253-260.

14. Millet GP, Faiss R, and Pialoux V. Point: hypobaric hypoxia induces different physiological responses from normobaric hypoxia. J Appl Physiol, 2012;112: 1783-1784.

15. Mounier R and Brugniaux JV. Counterpoint: hypobaric hypoxia does not induce different physiological responses from normobaric hypoxia. J Appl Physiol, 2012;112: 1784-1786.

16. Stray-Gundersen J, Alexander C, Hochstein A and Levine B. Failure if red cell volume to increase with altitude exposure in iron deficient runners. Med Sci Sports Exerc 1993;24: S90.

17. Constantini K, Wilhite DP and Chapman RF. A Clinician Guide to Altitude Training for Optimal Endurance Exercise Performance at Sea Level. High Alt Med Biol. 2017;18: 93-101.

18. Chapman RF, Stray-Gundersen J, and Levine BD. Individual variation in response to altitude training. J Appl Physiol 1998;85: $1448-1456$.

19. Wilber RL, Stray-Gundersen J and Levine BD. Effect of hypoxic "dose" on physiological responses and sea-level performance. Med Sci Sports Exerc. 2007;39: 1590-1599.

20. Garvican-Lewis LA, Sharpe K and Gore CJ. Time for a new metric for hypoxic dose? J Appl Physiol 2016;121: 352-355.

21. Levine BD and Stray-Gundersen J. Point: positive effects of intermittent hypoxia (live high:train low) on exercise are mediated primarily by augmented red cell volume. J Appl Physiol 2005;99: 2053-2055.

22. di Prampero PE. The energy cost of human locomotion on land and in water. Int J Sports Med 1986;7: 55-72.

23. Gore CJ, Clark SA and Saunders PU. Nonhematological mechanisms of improved sea-level performance after hypoxic exposure Med Sci Sports Exerc. 2007;39: 1600-1609.

24. Marconi C, Marzorati M, Sciuto D, Ferri A and Cerretelli P. Economy of locomotion in high-altitude Tibetan migrants exposed to normoxia. J Physiol. 2005;569: 667-675.

25. Chapman RF, Laymon Stickford AS, Lundby C and Levine BD. Timing of return from altitude training for optimal sea level performance. J Appl Physiol. 2001;91: 1113-1120.

26. Rice L, Ruiz W, Driscoll T, Whitley CE, Tapia R, Hachey DL, Gonzales GF and Alfrey CP. Neocytolysis on descent from alti- 
tude: a newly recognized mechanism for the control of red cell mass. Ann Intern Med. 2001; 134: 652-656.

27. Prommer N, Thoma S, Quecke L, Gutekunst T, Volzke C, Wachsmuth N, Niess AM and Schmidt W. Total hemoglobin mass and blood volume of elite Kenyan runners. Med Sci Sports Exerc 2010; 42: 791-797.

28. Bärtsch P and Swenson ER. Acute high-altitude illnesss. N Engl J Med 2013; 368: 2294-2302.

29. Burtscher M, Niedermeier M, Burtscher J, Pesta D, Suchy J and Strasser B. Preparation for Endurance Competitions at
Altitude: Physiological, Psychological, Dietary and Coaching Aspects. A Narrative Review. Front. Physiol. 2018;9:1504. doi: 10.3389/fphys.2018.01504.

30. Hopkins WG and Hewson DJ. Variability of competitive performance of distance runners. Med. Sci. Sports Exerc. 2001; 33: 1588-1592.

31. Padulo J, Oliva F, Frizziero A, Maffulli N. Muscles, Ligaments and Tendons Journal - Basic principles and recommendations in clinical and field Science Research: 2018 update. MLTJ 2018; 8(3): $305-307$. 